The University of San Francisco

USF Scholarship: a digital repository @ Gleeson Library |

Geschke Center

2016

\title{
An Investigation of Highly Identified Fans Who Bet Against their Favorite Teams
}

\author{
Nola Agha \\ University of San Francisco, nagha@usfca.edu \\ B. David Tyler \\ Western Carolina University, dtyler@wcu.edu
}

Follow this and additional works at: http://repository.usfca.edu/sm

Part of the Sports Management Commons

\section{Recommended Citation}

Agha, N., \& Tyler, B. D. An investigation of highly identified fans who bet against their favorite teams. Sport Management Review, 2016, http://dx.doi.org/10.1016/j.smr.2016.09.004

This Article is brought to you for free and open access by the College of Arts and Sciences at USF Scholarship: a digital repository @ Gleeson Library | Geschke Center. It has been accepted for inclusion in Sport Management by an authorized administrator of USF Scholarship: a digital repository @

Gleeson Library | Geschke Center. For more information, please contact repository@usfca.edu. 
An Investigation of Highly Identified Fans Who Bet Against their Favorite Teams

\author{
Nola Agha, ${ }^{a}{ }^{*}$ and B. David Tyler ${ }^{\text {b }}$ \\ * Corresponding Author \\ ${ }^{a}$ University of San Francisco \\ Sport Management Program \\ 2130 Fulton Street, KA241 \\ San Francisco, CA 94530 USA \\ E-mail: nagha@usfca.edu \\ Phone: 1-415-422-6642 \\ Fax: 1-415-422-6267 \\ ${ }^{\mathrm{b}}$ B. David Tyler \\ Western Carolina University \\ College of Business \\ Cullowhee, NC 28723 USA \\ E-mail: dtyler@wcu.edu \\ Phone: 1-828-283-0203 \\ Fax: 1-828-227-7414
}

For the published version please visit:

http://dx.doi.org/10.1016/j.smr.2016.09.004

To cite the pre-publication (online) version, please use:

Agha, N., \& Tyler, B. D. An investigation of highly identified fans who bet against their favorite teams. Sport Management Review, 2016, http://dx.doi.org/10.1016/j.smr.2016.09.004 
An Investigation of Highly Identified Fans Who Bet Against their Favorite Teams

\section{Highlights}

1. Some highly identified fans Bet Against their Favorite Teams (BAFT).

2. These non-normative behaviors are explored, described, and explained.

3. For some fans, financial gains offset a perceived impending emotional loss.

4. These fans Hedge Against Future Failure (HAFF) as a self-image management strategy.

5. Unlike BIRGing and CORFing, HAFFing is transactional, proactive, and private. 
An Investigation of Highly Identified Fans Who Bet Against their Favorite Teams

\begin{abstract}
Using a mixed-method exploratory approach we describe and explain the seemingly nonnormative behaviors of highly identified fans who Bet Against their Favorite Teams (BAFT). Axial coding of qualitative data from 190 survey respondents and two focus groups indicates the emergence of common themes allowing a typology to unfold that explains the motives for and against BAFTing. Results reveal that Gamblers BAFT for reasons un-related to fandom. Hedgers, on the other hand, BAFT precisely because they are fans; they offset a perceived impending emotional loss with a financial gain, a behavior we identify as Hedging Against Future Failure (HAFFing). This research expands the theoretical knowledge of indirect tactics of image management and introduces HAFFing as a transactional, proactive, and private coping mechanism utilized by highly identified fans to regulate their psychological health. Beyond the implications for researchers of self-image management, these results are applicable to global sport managers adapting to the rising prominence and societal acceptance of sport gambling.

Keywords: social identity theory, self-image management, self-concept, emotional hedging, gambling, consumer behavior
\end{abstract}


An Investigation of Highly Identified Fans Who Bet Against their Favorite Teams

\section{Introduction}

Through the lens of social identity and self-categorization theory, we understand that individuals define themselves in part by the groups with which they identify (Hogg, 2003; Turner, 1982). Given that social identity (or the "collective self") is a key part of one's selfconcept (Ashmore, Deaux, \& McLaughlin-Volpe, 2004; Sedikides \& Brewer, 2001), it follows that alignment with social groups can be used as a mechanism to maintain or enhance one's selfconcept (Abrams \& Hogg, 1988; Baumeister \& Leary, 1995; Tajfel \& Turner, 1986).

In the case of identification with sport teams, a fan is an individual with a psychological connection to a team (Funk \& James, 2001). A fan's psychological well-being is derived from processes such as the sense of belonging experienced when associating with others and the selfesteem gains garnered when a favored team wins (Wann, 2006). It is, therefore, logical for a fan to desire team wins and engage in normative fan behavior that helps associate the fan with others in the group, keeping in mind that normative group behaviors are not explicitly documented and vary across cultures (Hogg, 2003). Given these expectations, imagine our surprise when a passionate sports fan and alumnus of the University of Michigan recounted a time in which he bet that Michigan would lose against The Ohio State University in their annual football rivalry; in other words, he placed a financial wager that Ohio State would win. This action runs counter to North American-based conceptualizations of normative fan behavior, appears to advocate for a team loss, and, to many, is an inconceivable act of betrayal. Some colleagues shared our disbelief, suggesting that this "highly identified fan" must instead have been a "normal fan" prone to such folly, while other colleagues outside of North America seemed less bothered by the 
wager. The reality is that highly identified fans do bet against their favorite teams (BAFT) even though current academic models of highly identified fans do not seem to support or acknowledge that BAFTing could be possible, in any cultural context. This research aims to bridge the chasm between academic expectations and the realities of this peculiar fan behavior while also underscoring the potential impacts of BAFTing for sport organizations.

Professional sport teams' financial success is bolstered by highly identified fans' attendance and consumption behaviors (McDonald, Karg, \& Vocino, 2013; Wann \& Branscombe, 1993). Given that direct revenue generation derives from a stable fan identity, Trail et al. (2012) argue that "the knowledge of team identification should be a cornerstone of customer-relationship management" (p. 352). From this perspective, Doyle, Lock, Filo, Funk, and McDonald (2016) call for more research on the myriad identity maintenance strategies of sports fans, especially in cases where that identity may be threatened. Research on BAFTing helps answer this call as we identify more complex mechanisms by which fans maintain their identity. Research on BAFTing may be even more prescient with experts predicting that the U.S. could legalize sports gambling within the next five years (Cohn, 2015). Despite the popularity of sport wagering within other countries and the need for managers to strategize around fans' construction of their social identities, remarkably little is known about the ways in which highly identified fans use gambling to regulate their self-image.

From a scholarly perspective, the idea that a fan might wager against their favorite team has been mentioned in both the psychology (Massey, Simmons, \& Armor, 2011) and economics literatures (Bosman \& van Winden, 2002) in the context of decision making under uncertainty. In proposing future research, Massey et al. (2011) hypothesized BAFTing behavior might occur as a type of "strategic hedge against the emotional pain associated with a favorite team's loss" (p. 
280) but did not test the proposition. To explain the outcomes of lab experiments on the influence of emotions on behavior, Bosman and van Winden (2002) called the same behavior "emotional hedging" (p. 160). Thus, while it has been proposed that BAFTing could explain experimental results from emotional decision making, suggesting the behavior is possible is very different than studying it in practice. Our understanding of BAFTing remains at the incipient stage of development and we find this lack of deep research of the phenomenon to be a significant gap in the literature. This paper explores, describes, and explains the peculiar phenomenon of highly identified fans placing financial wagers that their favorite team will lose. In doing so we provide evidence to answer a series of important questions:

- Do highly identified fans really bet against their favorite teams?

- Where, how, and how often does this behavior occur?

- What are fans' motivations for this BAFTing behavior?

- How does BAFTing align with theories of fan behavior and fan identity?

The paper begins by discussing the theories that explain normative fan behaviors. We then use surveys and focus groups in an exploratory approach to describe the characteristics of BAFTing in terms of where, how, and how often it occurs. Next, axial coding of qualitative data in alignment with gambling motives, social identity theory (SIT), and other known behavioral measures of group association indicates the emergence of common motivational themes that allow a typology of BAFTers and non-BAFTers to unfold. An unintended outcome of this exploratory research is the identification of a new behavioral measure of group association that adds to our theoretical understanding of indirect image management (Wann, 2006). The paper concludes by offering suggestions for practitioners and future research directions.

\section{Existing understanding of fan identification and norms}


Before trying to understand BAFTers' motives, we must first examine why the prevalent view, particularly in North America, is that a highly identified fan would not BAFT. Fans are understood to internalize team success as personal success, basking in the reflective glory (BIRGing) of their teams' triumphs (Cialdini, Borden, Thorne, Walker, Freeman, \& Sloan, 1976), and to internalize team failures as personal failures (Wann, Melnick, Russell, \& Pease, 2001). Disposition theory suggests that the strongest reactions come from the most highly identified fans (cf. Sapolsky, 1980) who have a variety of affective, cognitive, and behavioral responses to loss in order to return to a state of positive psychological well-being. Reactive behaviors are expected to adhere to group norms and do not include self-criticism. Thus, we begin by examining some of the existing knowledge on prototypical behavior, reluctance to selfcriticism, and known responses to losing. We follow with known motives for gambling.

\subsection{Normative fan behaviors and prototypes}

Two main benefits of self-categorization and its associated social identity processes are self-esteem benefits and reduction in social uncertainty (Hewstone, Rubin, \& Willis, 2002; Hogg \& Terry, 2000; Turner, 1982). To reduce social uncertainty, highly identified individuals learn appropriate social behavior through the norms of their social groups. Further, individuals' adherence to group attitudes, feelings, and behaviors can result in greater social standing within the group (Marques, Abrams, Paez, \& Martinez-Taboada, 1998). Highly identified group members may seek to emulate the group prototype-a cognitive representation of the group's defining attributes and behaviors - in order to be seen and/or see themselves as exemplary members (Hogg, 2003; Jetten, Spears, \& Manstead, 1998). In the case of expansive social categorizations, such as a team's fan base, there are few explicitly documented norms and, thus, individual group members' conceptualizations of prototypical behavior may vary. Prototypes 
become what Hogg (2003) describes as "fuzzy sets" (p. 468) which leads to internal differentiation within groups. If fans are placing financial wagers that their team will lose, the fans' behavior may be interpreted as deviating from that of the prototypical fan and from the prescriptive norms of the group. Individuals seeking to adhere to the fan prototype should therefore eschew this behavior.

\subsection{Responses to losing}

Highly identified fans' self-esteem and identity are often influenced by team success (Van Leeuwen, Quick, \& Daniel, 2000). As such, these fans are known to suffer negative outcomes from a favorite team's loss due to the loss being viewed as a reflection of oneself, including decreased self-esteem, mood, and public image (cf. Hirt, Zillmann, Erickson, \& Kennedy, 1992). As the most highly identified fans are less likely to reduce their association with a poorly performing team (Branscombe \& Wann, 1992; Hirt et al., 1992; Wann \& Branscombe, 1990), they often engage in other reactive behaviors to deal with the loss, such as focusing on other aspects of the team (Roccas \& Brewer, 2002), derogating ("blasting") the opponent (Cialdini \& Richardson, 1980), or engaging in aggressive behaviors (Branscombe \& Wann, 1992). Ultimately, highly identified fans are understood to be motivated to take some action in the face of a loss to restore their positive self-concept (Wakefield \& Wann, 2006).

Wann (2006) refers to these behavioral responses to loss as coping strategies and summarizes them into five response sets, including Allegiance Bias and Manipulation of Associations with a Team. Sport scholars have paid significant attention to studying the ways that fans manipulate their associations with their teams. For example, we have seen that after a win, fans can BIRG or Cut Off Future Failure (COFF) (Wann, Hamlet, Wilson, \& Hodges, 1995); whereas after a loss, fan options include Cutting Off Reflected Failure (CORFing) 
(Snyder, Lassegard, \& Ford, 1986) and derogating rival out groups by Blasting (Cialdini \& Richardson, 1980). These manipulations of group associations are referred to as indirect tactics of image management and include a variety of behaviors related to positive and negative connections to favorable and unfavorable others (Cialdini, 1989). Most of these strategies are derived to deal with the aftermath of a team loss, yet none of these coping strategies would predict a fan placing a bet that their favorite team will lose. Section 5 pays considerable attention to reconciling BAFTing's place within these fan coping strategies.

\subsection{Gambling motives}

Gambling's place at the center of BAFTing suggests that gambling motives may inform the interpretation of our data. Gambling motives are traditionally based on wealth maximization, utility maximization, and risk preferences (Conlisk, 1993), though recent research suggests that sport gamblers are motivated by experiential utility (Mao, Zhang, \& Connaughton, 2015) and consumption benefits (Humphreys, Paul, \& Weinbach, 2013) more so than financial gain. The cross-sectional approach of Neighbors, Lostutter, Cronce, and Larimer (2002) identified 16 gambling motives, which we simplify into four commonly accepted categories: enhancement, social, coping, and monetary. Enhancement motives describe those who gamble for fun or excitement (cf. Back, Lee, \& Stinchfield, 2011; Platz \& Millar, 2001). Social motives include gambling to socialize with other people or gambling because one's friends do (cf. Lee, Lee, Bernhard, \& Yoon, 2006; Stewart \& Zack, 2008). Coping motives include escaping from daily routines, to relax, or to forget one's worries (cf. Loroz, 2004; Stewart \& Zack, 2008). Lastly, monetary motives involve winning money (Park, Yang, Lee, Jang, \& Stokowski, 2002). ${ }^{1}$ None

${ }^{1}$ A reviewer pointed out that these gambling motives are also known motives for fandom (Wann, 1995). Despite this interesting overlap, we focus on already highly identified fans (regardless of their initial motive for fandom). Although it is possible that some were initially drawn to sports for economic or gambling motives, there is 
of these studies assess the team a gambler is betting for or against in reference to their fandom.

\section{Methods, instruments, and samples}

We conducted mixed methods research to explore, describe, and explain BAFTing behavior from the perspective of highly identified fans (Denzin \& Lincoln, 2011). The mixedmethod research design included an online survey, which collected both open-ended qualitative data and quantitative data, and two focus groups (Creswell, 2013) which allowed us to expand our results (Rudd \& Johnson, 2010). An exploratory and inductive approach was used with the qualitative data because no existing theory describes or explains BAFTing behaviors outside of laboratory settings.

\subsection{Survey}

A Qualtrics online survey sought to confirm that BAFTing does indeed exist as well to explore how, where, and when it occurs. As an important research question involved whether fans who claim they BAFT are highly identified, the survey began with seven questions from Wann and Branscombe's (1993) Sport Spectator Identification Scale to determine respondents' levels of identification, where 56 is the maximum identification score. Remaining questions focused on betting frequency, behavior, and motivation, with the emphasis that we were not asking about wagering related to fantasy sports. Questions assessing frequency of sport betting asked respondents to approximate the total number of sport-related financial wagers that they placed in a given year and, for those who identified that they BAFT, the number of times per venue (casinos, bookies, friends/family, office pools, online gambling sites, and others) that they 
placed financial wagers that their team would lose. These questions which might normally be answered with quantitative data were collected as open-ended responses because we had no preconceived notions of how often they would occur. All responses were re-coded to numerical values to generate minimum, mean, and maximum values.

To address research questions on motives, questions that asked why participants did or did not BAFT were similarly open-ended, such as "Explain why you placed a financial wager that your favorite team would lose" and "Describe the last time you placed a financial wager that your favorite team would lose." Those who reported never BAFTing were instead asked "Why have you never placed a financial wager that your favorite team would lose?" Open-ended questions provided a richer understanding of why BAFTing occurs (cf. Inglis, 1992) ultimately enabling us to describe how BAFTing behavior aligns with theories of fan behavior, fan identity, and gambling motives.

Each author independently coded these open-ended responses resolving differences with discussion. Given the exploratory nature of this research, codes were generated inductively from the data and axial coding grouped the codes into motivational themes. While the codes were generated strictly from the data, the identification of themes was done while working dialectically between the literature and the data, particularly within the areas of prototypical fan behavior, self-criticism, responses to losing, and gambling.

As defined in Section 1, BAFTing is conducted by highly identified fans and by fans who are willing to wager on sport in general. To identify these individuals, we purposively sought participants who had a high likelihood of being highly identified fans (cf. Coyne, 1997) by recruiting through announcements in undergraduate and graduate sport management classes at two U.S. universities. A total of 360 useable surveys were obtained through voluntary 
participation and respondents received no incentives for their involvement. Participants ranged in age from 18 to 40, all held at least a high school diploma or equivalent, and the graduate students (55\% of the respondents) had experience working in the sport industry through full-time positions or internships as required by their graduate program. Of the 360 responses, 313 were highly identified fans of which $39 \%(n=123, I D=46.7)$ had never placed a financial wager and were subsequently discarded from further analysis. The highly identified fans who had placed financial wagers on sports were the focus of our study $(n=190, I D=48.2)$ of which $58 \%$ were graduate students. These highly identified fans who had gambled were classified as either BAFTers or non-BAFTers based on their response to the question, "Have you ever placed a financial wager that your favorite team would lose?" As expected, the majority of highly identified fans who bet were non-BAFTers $(n=150, I D=48.2)$ and only $21 \%(n=40, I D=48.3)$ were BAFTers.

\subsection{Focus Groups}

A total of 12 focus group participants were recruited through their completion of the survey and consisted of both BAFTers $(n=5, I D=49.4)$ and non-BAFTers $(n=7, I D=47.8)$. Prior to the focus group they gave consent for both participation in and digital recording of the conversation. Each focus group lasted approximately 35 minutes and participants were given pizza during the conversation as compensation for their time.

The themes and results from the qualitative survey data were used to generate semistructured questions that guided the two focus groups. Core questions involved why a participant did or did not BAFT. Probing questions served to uncover deeper understanding of where, how, and why participants BAFTed. The mix of highly identified fans who had and had not BAFTed led to an engaged discussion of the role of BAFTing in relation to fandom. Each group defended 
its own position and, in the process, provided valuable insight into their motivational thought processes.

Remarks from the focus groups were transcribed. Each author independently coded the transcripts, again generating codes inductively from the data. Those codes were then compared with the codes and themes identified during the survey data analysis. Though the authors' approach lent itself to the emergence of new findings, no additional themes emerged. Rather, the focus groups served as useful validation of the themes that emerged from the survey. <insert Table 1 about here>

\section{Findings}

\subsection{Who? Where? How? How often?}

There were no statistically significant differences between the social identification scores of BAFTers and non-BAFTers in either the survey or focus groups (Table 1). This indicates that BAFTing behavior is not related to one's level of identification and supports the assertion that BAFTers are highly identified fans.

Most BAFTers utilized multiple venues for wagering. Sixty percent reported placing bets with friends and family, as captured by comments such as, "Me and my dad bet fifty dollars on the panthers [sic] and Cowboys game last year" (SR $\# 210)$. Online betting (38\%) and sports books $(35 \%)$ were the second and third most common venue to BAFT. Online betting had the highest number of overall bets, followed by friends and family. It should be noted that these channels of wagering are likely more common in the U.S., where gambling is illegal in nearly all states, than in other countries with more prevalence of sport gambling (e.g., United Kingdom or

\footnotetext{
${ }^{2}$ Throughout the paper we refer to survey respondents as SR and focus group members as FGM.
} 
Australia).

When asked to "Describe the last time you placed a financial wager that your favorite team would lose," participants reported BAFTing in a wide variety of cases including office pools and trips to Las Vegas (where gambling is legal). Survey respondent \#214 reported BAFTing, "At a Las Vegas Sportsbook this summer. My team was struggling and the Orioles were the underdogs and red hot at the time." BAFTing was also reported during playoff or championship games, which is consistent with findings of higher volumes of sports gambling at the end of the season (Humphreys et al., 2013).

Table 1 illustrates the BAFTers in our sample placed a higher average number of sportrelated wagers each year than non-BAFTers. But, as we describe in Section 4.2.1.2., the averages of BAFTers are inflated by the presence of individuals who BAFT because they are first and foremost gamblers, not because of reasons related to fandom. The number of all-time BAFT wagers ranged from 1 to 111 with a median of 4 . The range and median indicate a spread of light, medium, and heavy gamblers.

\subsection{Why and why not?}

Open ended survey responses and focus group remarks were coded to understand why some fans BAFT and some do not. Table 2 shows sample open codes and how they were aggregated during axial coding. The codes are grouped by respondents' attitude toward BAFTing, which illustrates the different language and motives used by these groups. <insert Table 2 about here>

Through the coding process, themes manifested themselves in four combinations, allowing the emergence of a typology of belief profiles that explained why participants did or did not BAFT. The way respondents interpreted and acted on BAFTing was classified into four 
different types of individuals summarized in Table 3; Hedgers and Gamblers engage in BAFTing while Deniers and Objectors do not. All four types of fans share the desire for their team to always win, a result consistent with their high levels of fan identification. Likewise, game results have a similar impact on all respondents' self-concepts as both groups' members' social identities are entwined with their teams (Ashmore et al., 2004).

Where BAFTers and non-BAFTers differ is in their views on acceptable fan behavior, their optimism in predicting game outcomes, and in their ability to use money as a reasonable compensation for emotional loss. The remainder of this section uses quotes from both focus groups and open-ended survey questions to provide descriptions of themes that help understand the BAFTing phenomenon. We begin each section with an overall summary and then describe the particulars of that group.

<insert Table 3 about here>

\subsubsection{BAFTers}

While there are distinctions among the two types of BAFTers, Hedgers and Gamblers, all BAFTers share three key qualities: the perceived knowledge that their team can (or will) lose; a view of the prototypical fan that does not negatively implicate the act of gambling against the team; and the desire for their favorite team to win even if they have bet against the team.

Believing that the team can lose is a necessary condition of BAFTing. If a loss were inconceivable, betting on a loss would not be an option, as is the case for the Deniers described further below. In quite the opposite way, respondents report BAFTing when certain that their team will lose, a belief they attribute to their superior knowledge of their team. For example, when explaining why they engage in BAFTing, respondents say, "Because I know my teams [sic] strengths \& weaknesses better than other teams and I know when they have a bad match- 
up" (SR \#89) and "Many starting players were out and as a fan I knew that they could not pull off the win" (SR \#130). What the participants repeatedly refer to as "knowing" is consistent with past research that highly identified fans' believe they have greater objective knowledge about their teams (Wann \& Branscombe, 1995). The conclusion that the team will fail is not unique in itself, but the action that stems from this knowledge (the BAFT) is unique.

This leads to the second commonality among BAFTers: their ability to reconcile being a "true fan" with placing a bet that their team will lose. SIT predicts acquiescence to the group prototype (Hogg, 2003) and, for sport fans, that group prototype of being a true fan typically prohibits BAFTing, particularly in the North American context. From the BAFTer's perspective, however, betting against one's team is not incompatible with being a prototypical fan. Said one respondent, "If you're thinking rationally, yeah, I don't think it impacts your fandom of a team by betting against them" (FGM \#10); another commented, "When you know your team as a true fan, you know when they have a good chance at losing" (SR \#57). For this respondent, a dominant trait of the "true fan" prototype is knowledge of one's team. Thus, the act of tying potential financial loss to team performance is interpreted as a demonstration of the veritable knowledge possessed by true fans rather than a betrayal of team loyalty.

Other fans resolve their BAFTing behavior by separating the wagering process from the construction of fan identity, typically describing the separation through terms like "logic" and "emotion." Survey respondent \#159 concisely stated, "I'm logical," while more verbose respondents stated, "Being a fan is irrational, so betting is rational, you bet with your mind, you root for a team with your heart" (FGM \#10) and "because they're going to win or lose regardless, I might as well capitalize monetarily on that outcome" (FGM \#2).

The third commonality among BAFTers is something shared with non-BAFTers: the 
desire for their team to win is unwavering. Respondents made it clear, both in private responses on surveys and when confronted by non-BAFTers in focus groups, that BAFTing did not make them root any less devoutly for their team to succeed. This is captured in the following statement: "When I wager against my team (which is seldom), it does not take away at all from my desire for my team to win. $100 \%$ of me desires that my team win and that I lose my wager" (SR \#21). Another said, "I'm rooting for [my team] to win and so I lose my bet. If they win and I lose my bet I'm really cool with that; it makes me happy" (FGM \#7). The conclusion from these statements is that BAFTers' first preference is to lose their bet and enjoy a team victory. But, failing that, they are comfortable accepting financial gain in the wake of their team's loss.

BAFTing behavior may seem surprising based on SIT, but it becomes consistent when understood through the internal interpretations of the action by BAFTers. BAFTers combine their reconciling of their fan identity with their perceived knowledge of a team loss to proactively tie financial outcomes to their beliefs. The objectives for taking this next step, and the thought processes that go into the decision process, are what distinguish the two types of BAFTers: Hedgers and Gamblers. ${ }^{3}$

\subsubsection{Hedgers}

Like all BAFTers, Hedgers begin with a certainty their team will lose based on their superior knowledge of the team, a feature they describe as "knowing" that their team will lose (Wann, Morris-Shirkey, Peters, \& Suggs, 2002). The essential quality of Hedgers is the ability to recognize that the team's impending loss will generate a decrease in their emotional state and that

\footnotetext{
${ }^{3}$ We identified one other BAFTer who did not fit neatly into the above classifications. This bettor used BAFTing as a form of social justice to "punish" teams for making decisions with which the individual disagreed. This BAFTer aligns in some ways with Pons, Giroux, Maltese, and Mourali's (2014) view of dysfunctional fans who have a lovehate relationship with their favorite team, yet we only observed one respondent who fit this description. Further investigation will need to be conducted to better understand such individuals.
} 
they can take action to mitigate that loss. That is, these fans are managing their self-concept by proactively regulating their emotions. Said one respondent, "If you're going to be depressed, why not be depressed with a little bit of money?" (FGM \#5). Another BAFTer described it as a coping strategy by saying, "If my team loses, then the financial winnings would help me cope with the loss" (SR \#241). A focus group participant stated, "I bet against my team and I see it as a win-win. If they win and I lose my money then I'm happy they won. And if they lose I'm sad that they lost but I won money" (FGM \#7).

The behaviors described by these respondents are hedges. A hedge is a financial technique designed to offset the risk of one investment by making another opposing investment. The hedge reduces the impact of a possible negative future event in the same way that gaining money may reduce the emotional loss after a team's defeat. While a hedge cannot prevent a negative event from occurring, it can reduce the impact of the negative event if it does occur. By definition, a hedge also reduces the potential gain if the negative event does not happen (e.g., if the team actually wins, the Hedger is happy, but loses some money from the bet). We found that Hedgers explain their behaviors and emotions in exactly these terms. For example, when describing why s/he BAFTs, SR \#108 stated, "Because if my team wins I feel happy even though I lost money, and if they lose at least I win some money."

The Hedger's decision process can be illustrated as a series of ranked preferences (see column three in Table 3). It starts with a self-belief in greater objective knowledge that their team will lose and that this loss is the worst possible outcome ("Loss"). A better outcome is for the fan to gain some money as a result of the loss - an outcome that is achieved by BAFTing ("Loss+\$"). Again, this hedge cannot prevent a negative event (the loss) from occurring, but it can reduce the impact of the negative event if it does occur. A survey respondent stated s/he 
BAFTs because, "I knew they were going to lose so I was making a business decision. Also to offset the sting of a loss, because in a way I still won something. It's like hedging a bet" (SR \#301, emphasis added). If the Hedger is wrong and the team unexpectedly wins the game, this win plus an associated financial loss is still a better overall outcome than a team loss plus an associated financial gain ("Win-\$"). This order was developed through interpreting quotes such as, "If they lose I get money. If they win I get happy. Its [sic] a win-win, just that one of them is a better win" (SR \#141) and "It just makes me feel good if they win and I lose money" (FGM \#7). The best case scenario is for the team to win without the fan having placed a bet ("Win"); but, because of the Hedger's belief in their superior knowledge that the team will lose, the Hedger does not see the best case scenario as a realistic possibility and is willing to accept a loss of money to protect against the most likely outcome (a team loss).

Hedgers appear to be engaging in emotional hedging, using financial gain as part of the process. While a team loss represents a hit to one's social self, the financial success provides a compensating reward. In simpler terms: money is not buying happiness, but it is offsetting sadness. For example, FGM \#2 stated, "if my team loses it's like, 'Aw, they lost.' But, 'Hey, I won some money.' It's like it [the financial win] kind of negates that [the team loss]." Likewise, another participant described the emotional hedge thusly: "It was a playoff game so stakes were higher and I felt... at least I'll [sic] emotionally won't go crazy if they lose and I make some money. But the other way I'm fine with that too--they'll be going to a Super Bowl!" (FGM \#9). The previous respondent is not alone in BAFTing more around pivotal games. Respondents cited the greater potential for emotional letdown in big games as making hedging all the more valuable. For example, "I've done it in pivotal games. It turns into a win-win situation. If my favorite team wins, I can celebrate the victory. And if they lose, at least i'm [sic] not coming out 
of it empty handed" (SR \#23). It is clear from these statements that Hedgers are able to conduct an exchange calculation between financial gain and emotional loss; as will be noted below, not all fans possess Hedgers' emotional/financial exchange rate.

\subsubsection{Gamblers}

Whereas the first type of BAFTer was seeking to regulate emotions, the second type of BAFTer, the Gambler, is one for whom the financial gains from gambling take prominence over affiliation as a fan. For example, "I look for the lines. I don't seek out my team. I take the best bet" (FGM \#2). Instead of focusing on perceived insider knowledge of wins and losses, one respondent stated, "Real gamblers play the odds and not their favorite teams" (SR \#142). Choosing the wager that makes the most financial sense implies a complete disconnect between betting and fandom. We see evidence of this in comments such as, "Sometimes I have so much stuff going, parlays and stuff, as I'm watching a game, I have no idea whether or not I chose [my favorite team]" (FGM \#2).

In terms of the gambling motives identified in Section 2.3., the BAFTers we classified as Gamblers are best described as exhibiting enhancement and monetary motives. In terms of enhancement, focus group member \#2 stated, "It makes games that don't matter really fun to watch." Later in the focus group, he explained, "See, what makes it fun for me is my emotions being in flux." These comments indicate that enjoyment of watching his team play is heightened by gambling, even when the outcome may result in losing money. The enhancement may even come from improving one's self-concept through seeing oneself as a better gambler, a psychological benefit seen among experienced gamblers (Loroz, 2004). Through viewing gambling as hedonistic consumption, Gamblers place a priority for gambling over their fandom and we see that the fun from winning a bet is separate from the enjoyment of being a fan. 
Monetary motives were also recurrent among this group. Survey respondent \#191 explained, "Even though I am a die hard [sic] Tar Heels fan, when money is involved I will always go for the team that is better or has the better chance to win." Another survey respondent stated, "I'm a huge 49ers fan but I'm even more of a fan of money" (SR \#1). There was clear evidence that money was a priority: "For me, particularly in the regular season, no one game is more important than me winning an amount of money" (FGM \#2).

Common among all of our Gamblers is that their motives for BAFTing are uniquely gambling motives and not related to their fan identity. Gamblers do not feel constrained by adherence to a fan prototype, at least not one defined by wagering. While all BAFTers compartmentalize betting and fanship to some degree, neither the act of betting nor the outcome of the bet impacts Gamblers' self-image as fans. One respondent, who reported gambling 1,500 times per year, stated that any sport wagering is "about making money, not who your favorite team is" (SR \#277).

For the Gambler, the BAFTing decision process starts with the desired gamble - whether the team wins or loses is relevant only insomuch as it affects the bet. There is no relationship between outcomes of gambling and the feeling of fanship as a result of team performance. In Table 3, we illustrate the Gambler's decision process with a pipe to indicate the wall between the two processes: the gamble ("\$") and the game outcome ("Win or Loss"). While gamblers are BAFTing, they are not motivated to do so because of reasons related to fandom.

\subsubsection{Non-BAFTers}

The most enduring feature of a non-BAFTer, and the one that provides its name, is that these fans do not place wagers that their favorite team will lose. While there are distinctions between the two types of non-BAFTers, they share three key views: thinking about BAFTing 
creates an internal conflict, superstition is an important reason to not BAFT, and they believe that BAFTers root against their favorite teams.

For non-BAFTers, BAFTing would result in internal conflict as it equates to criticism of one's team and, in turn, oneself. This conclusion was determined through comments such as, "I would not bet against my team because that would indicate that I have no loyalty nor [sic] faith in my team even if they are competing with the best team in the league" (SR \#91) and "[I] feel as though betting against one's team would be a great betrayal" (SR \#136). It is clear that when faced with the possibility of BAFTing, non-BAFTers expressed notions of cognitive dissonance. For example, "I would feel even worse if I placed a bet on my favorite team to lose and they ended winning [sic]. I would lose out on my bet and feel guilty that I questioned my team's ability to win" (SR \#111) and "I can't justify the means to an end on that one. I'm winning money if I win my bet against my team, but losing a little bit of my soul in the process" (SR \#93). While Hedgers and Gamblers are able to reconcile their betting behavior with their views of themselves as fans, it is clear that non-BAFTers cannot resolve such actions with how they present themselves as fans.

The views of non-BAFTers are consistent with the traditional understanding posited by SIT wherein BAFTing would be thought of as self-criticism. Where one's construction of one's social self equates team failure with personal failure, BAFTing is seen as akin to predicting failure in oneself. One respondent summed up this view thusly: "I don't understand it. Like, I never bet against myself, so I don't know why I'd bet against my team" (FGM \#12).

Superstition about how fans' actions affect team performance is the second feature prominent among non-BAFTers. Consistent with the definition of Wann et al. (2013), nonBAFTers feared that their bets, and their desire for the bets to pay off, would negatively affect 
team performance. Respondent comments showed concern over jinxing the team, as evidenced by statements such as, "I think it would be bad luck/karma to bet against them!" (SR \#119), "On a superstitious note, it would probably bring bad luck to you and/or the team" (SR \#136), and "It feels weird to bet against my favorite team. Like if I bet against them they will lose somehow" (SR \#121). It should be noted that we perceived respondents' superstition as distinct from comments about "faith" or "belief." The latter terms were used predominantly when discussing how fans should behave, and thus we aligned these terms with fans' construction of the true fan prototype. The superstitious comments, on the other hand, implied the individual seeing his or her will as affecting the game outcome.

Finally, the third feature common among non-BAFTers is the idea that betting against one's team is equivalent to rooting against one's team. This was particularly apparent in the results from the survey, which was completed in private and, thus, respondents were not exposed to the perspective of BAFTers. Said one respondent, "I would never bet for them to lose because that would mean I'd have to root against them to win my bet. My team winning is more important than winning a financial wager" (SR \#146). Another wrote, "it is not possible for me to want my team to lose so I can gain something else. Doesnt [sic] make sense to me" (SR \#152). When faced with BAFTers in the focus groups, this same belief was present. Thus, even after BAFTers explained their position that one does not have to root against one's favorite team, nonBAFTers still could not conceive that a true fan could BAFT and concluded, "I don't think [a BAFTer] loves the team the way I love the team" (FGM \#12).

The incredulousness of non-BAFTers derives from the two groups' differing conceptualizations of the true fan prototype. Recall that though prototypes can be real people, it is more often the case that prototypes of large, nebulous groups (e.g., sport fans) are idealized 
abstractions of the group ideals (Hogg \& Terry, 2000). Because of this, each member of the group may have different conceptualizations of the prototypical fan, and we see this in how our respondents define the actions of "true fans." For BAFTers, that conceptualization does not include the idea that one shall not bet against one's team; in fact, some BAFTers view gambling as illustrative of being even better fans because it demonstrates their superior knowledge. In contrast, non-BAFTers' definition of the prototype prohibits betting against the team, though the nuances in that view help to differentiate the two types of non-BAFTers: Deniers and Objectors.

\subsubsection{Deniers}

While individuals in other groups may weigh the pros and cons of BAFTing and take action accordingly, for Deniers, BAFTing is a forbidden behavior in their view of a fan and, thus, not something they would consider doing. Several aforementioned quotations illustrate this position, as well as these: "I choose never to bet against my favorite team because that would require myself to root against them, and that runs counter to the idea of being a true, loyal fan" (SR \#157), and "I never go against them and [I] believe thats [sic] what a true fan is" (SR \#101).

These individuals believe that the prototypical definition of a fan does not include the option of BAFTing and, instead, subscribe to the notion that a "true fan" exhibits themes of loyalty, purity for the game, trust, and respect, which non-BAFTers see as antithetical to placing a wager against one's favorite team. As such, Deniers do not consider BAFTers to be prototypical, true fans. For example, when asked about the possibility of BAFTing, one respondent said, "I don't believe a 'real' fan of the team would ever do so" (SR \#171). At a deeper level, these fans believe that seeing themselves as a loyal fan is always more important than money: "I wouldn't bet against my favorite team anyways because you can't really be a true fan if you are selfishly look [ $\mathrm{sic}]$ out more and value your own monetary interests over your loyalty to 
the team" (SR \#148). Similarly, when discussing BAFTing in the focus group, a Denier said, "I wouldn't want to gain money from it... I just don't see how you wrap your mind around it. He's [the Hedger] totally a lesser fan than I am" (FGM \#12). This quote is particularly illustrative of Deniers' view of themselves at the center of the fan group, or in Unruh's (1980) words, as Insiders in the social world of fandom.

Another feature of Deniers is the unwavering optimism that their team will win. This belief in the team ties strongly to the idea that actions or thoughts to the contrary are forms of betrayal. That is, the non-BAFTer's image of the prototypical fan is of one who cannot have any stake in seeing one's team falter: "I've never thought they were actually going to lose before the game, all losses are upsets!" (SR \#43). Said another Denier, "I have never placed a financial wager that my favorite team would lose because no matter what, I truly believe that they can always win" (SR \#122).

This optimism in team success prohibits further mental consideration of emotional hedging. That is, if a Denier always believes in a win, then there is neither space for contemplating a potential future emotional loss nor any means to proactively correct it. This is well illustrated by the respondent who said, "I believe every time my favorite team steps on the field, they have a chance to win. Even if the odds were stacked against my favorite team, my desire and passion for my team to win would outweigh any thoughts of placing a 'financial wager' on my team to lose" (SR \#111). This is illustrated in Table 3 as a win being preferable to a loss, with no consideration of how BAFTing might impact that relationship since "Loss $+\$ "$ and "Win-\$" are not options in Deniers' mental calculations.

Whereas BAFTers contemplate the possibility of a loss and opt to wager, Deniers simply focus on the impending win. In this way, they differ from the other non-BAFTers (Objectors), 
who contemplate the possibility of a loss but elect not to wager.

\subsubsection{Objectors}

An Objector can conceive that his team will lose, and that he will suffer after the loss, but he still chooses not to bet. For Objectors, the monetary gain does not compensate for the emotional loss. A good illustration is the Objector who said, "I wouldn't bet against my favorite team because it would ruin the enjoyment and excitement of the game. Yes, I could off set the feeling of a loss if I bet on them, but... I'd rather just keep my money" (SR \#105). Another Objector referred to this feeling as being at "emotional base zero," and followed with, "When I'm watching sports, I don't want to be 'no emotion' towards it. I want to have an actual interest to root for them to win or root for them to lose" (FGM \#3). Others added, "I do not value a monetary prize over the win of my favorite team" (SR \#257) and "It is a lose-lose situation. Either I lose money or my favorite team loses, so there is no point" (SR \#267). This quote is interesting as it contrasts the Objector's lose-lose view of BAFTing with the Hedger's win-win perception of the same activity. In a focus group, an Objector speaking to a Gambler observed, "I can see how the betting can make a neutral thing pretty exciting" (FGM \#4). The Objector was not advocating or agreeing with the Gambler's position, but showed a willingness to ponder the possibility of BAFTing for themselves.

Unlike the Denier, an Objector's view of a prototypical fan is broad enough to recognize the possibility that others can place wagers against their favorite teams without compromising their fanship. That is, an Objector's definition of a "true fan" includes those who BAFT_it is just not an action from which he or she derives benefit. Said one respondent quite simply, "I concluded that I would [not] benefit from the bet/wager" (SR \#86). Emotional hedging does not make sense to Objectors because they do not have an exchange rate between money and 
emotions that make it possible to offset emotional loss with financial gain. However, they recognize that it may have that effect for others. In Table 3 this is illustrated by the idea that a loss ("Loss"), a loss with financial gain ("Loss+\$"), and a win with a financial loss ("Win-\$") are all equivalently inferior states for an Objector; a win ("Win") is always preferable to each of those lesser options.

\subsection{Understanding BAFTers and Non-BAFTers}

Non-BAFTers (Deniers and Objectors) fit within SIT's classic view of sport fans; their self-concept suffers from team losses and they cannot use monetary gains as a way to offset those losses. BAFTing, on the other hand, has two unique motivations. Gamblers are motivated by elements such as monetary gains, fun (enhancement), or socialization, rather than being motivated to BAFT by any features of fandom. Hedgers, on the other hand, BAFT because they are fans, a process which offers us a new perspective on fans and emotional regulation. These fans understand that their self-concept suffers when their team loses, but rather than resorting to traditional post hoc actions like CORFing or Blasting, these fans engage in a proactive hedge to regulate their emotions.

\section{Hedging Against Future Failure (HAFFing)}

Upon cursory examination through a SIT lens, it appears that Hedgers are rooting for failure by a part of their social selves. But, as the description and quotes above make clear, this is not how Hedgers perceive themselves. Hedgers are dealing with a loss, and in their minds they are not self-criticizing. Their rooting interests remain unchanged, they still bask in the glory of team success, and they still consider themselves true fans as their definition of the prototypical fan does not prohibit BAFTing. Their social identity is still defined by their fanship, their self- 
concept is enhanced or diminished by team performance, and they seek to engage in behaviors to restore their self-concept. The difference is that Hedgers protect their self-concept from the negative impact of their team's loss through the gains achieved from wagering.

All of these unique behaviors and beliefs of Hedgers allow us to identify Hedging Against Future Failure (HAFFing) as a new form of proactive behavioral self-image management. HAFFing occurs when, in advance of a potential loss and the corresponding negative impact on one's self-concept, one takes action to preserve one's sense of self should a loss occur. The term "emotional hedging" (Bosman \& van Winden, 2002) is a form of HAFFing wherein a fan proactively places a bet so that a financial gain offsets their emotional loss.

In Table 4, HAFFing is compared to other existing strategies of self-image management. These behaviors are classified by Wann (2006) as a form of manipulation of the association a fan has with a team. From Cialdini's (1989) perspective, these behaviors are designed to manage both one's public and private self-image.

<insert Table 4 around here>

As Table 4 makes clear, almost all of these notable strategies for self-image management are reactive (i.e., after the outcome of the game) and engaged in publicly. HAFFing, however, is performed proactively and is typically private. It requires anticipation of a loss, understanding of the negative effect of that loss on the self, and willingness to take action to manage one's selfconcept in the face of the expected loss. Both Cialdini (1989) and Wann (2006) make the point that these image management tactics are not only designed to affect perceptions of others, but also that "the self is often strategically presented to the self " (Finch \& Cialdini, 1989, p. 229, italics in original). Certainly, HAFFing is designed to affect oneself more than others.

The self-image management strategy analog that is closest to HAFFing is COFFing, but 
there are two key distinctions. First, COFFing is marked by the individual's decision to not BIRG after a win. A COFFer forgoes BIRGing in order to protect himself from future association with the team when the team eventually loses. The HAFFer, on the other hand, takes action in advance of a game regardless of the past game's outcome. The second distinction is that, unlike the COFFer, the HAFFer still allows himself to engage in other self-management behaviors. For example, he can BIRG after a previous win, even in the aftermath of a game on which he placed a wager. The COFFer minimizes the potential negative impact on his social self by distancing himself from the team identity, but the HAFFer can still be highly, publicly identified with his team and enjoy the self-esteem benefits that come from BIRGing.

It appears HAFFing is more common than we would expect based on the North American view of the fan prototype. The robust array of coping mechanisms available to highly identified fans to deal with a team loss suggests that there is a very real need to regulate emotions and psychological health, but also that the entirety of coping mechanisms are not yet identified.

\section{Discussion, Contributions, and Future Research}

HAFFing lies at the intersection of several scholarly fields: it is an action taken under uncertainty (decision making), regarding the unknown outcome of a sporting contest (sports economics), and its motivation lies in the maintenance of a fan's self-image (social identity). While we approached our qualitative inquiry primarily from a social identity standpoint, our findings relate to both sport management and other adjacent fields.

In regard to social identity, there are significant implications of HAFFing as a new form of self-identity management. First, as illustrated in Table 4, it is the first form of self-identity management that is entirely proactive. Second, it can exist privately, which is particularly 
relevant within the North American context. Third, it is transactional. In the model of fan engagement developed by Yoshida, Gordon, Nakazawa, and Biscaia (2014), impression management techniques were considered forms of non-transactional spectator sport engagement behaviors. It is now clear that image management is not entirely a public, reactive, or nontransactional process. Since professional sport organizations depend on highly identified fans as a consistent source of revenue, the transactional nature of HAFFing should be of acute interest.

In regard to decision making, Massey et al. (2011) conclude that "people are optimistic in their predictions - they judge preferred outcomes to be more likely than non-preferred outcomes" (p. 279), yet our investigation into BAFTing makes it clear that this conclusion only applies to the non-BAFTing subset of fans. Hedgers prefer a winning outcome but optimism does not blind them to the real likelihood that their team might lose. Similarly, an analysis of reference dependent preferences in attendance demand assumes that a fan is capable of calculating a marginal utility (Coates, Humphreys, \& Zhou, 2014), yet we found Deniers have blind optimism that prohibits a marginal utility calculation whereas Hedgers do not. Further, this research illustrates how both economic and psychology models should consider a fan's personal adherence to (and definition of) the fan prototype as a variable in their decision making models.

In regard to the management of sport, because team losses are an unavoidable component of competitive sports that create threats to team identity, managers should both monitor and assist in maintaining strong fan identities (Trail et al., 2012). They can do so through an understanding of SIT within the context of BAFTing as well as an understanding of the BAFTing action itself. For interacting with HAFFers, this could mean offering alternatives to gambling to help these fans compensate for a team's on-field loss (Doyle et al., 2016). For example, teams could offer free concessions, return some portion of the ticket purchase, or a 
team sponsor could throw a party where fans can socialize and reinforce their shared identity despite the team's loss. If these were not sufficient to meet a HAFFer's identity maintenance needs, supporting the HAFFer's wagering may be more useful and profitable, especially as North American leagues shift to a pro-gambling stance. In comments about the NBA, Commissioner Adam Silver stated gambling "creates more engagement" ("Silver Explains", 2015), which can explain why new NBA arenas are being built with gaming lounges. As the NBA and other professional leagues become more accepting of gambling entities (Lefton, 2015) and invest in popular daily fantasy leagues (Fisher, 2015), they can both increase engagement and assist highly identified fans in maintaining their identity.

Given the differing ways in which fans define normative behaviors of the group, team managers should also consider the perspective of Deniers who could interpret the team's progambling stance as violating the prototype of a true fan. Sport organizations that build increasingly close relationships with gambling activity may want to balance those moves by shaping fans' construction of the group prototype to include BAFTing. For example, promotional materials touting gambling lounges could showcase fans who would otherwise meet the prototypical standards. Group members redefine group norms and values based on the behaviors of the group's core members (Hogg, 2003), thus seeing individuals perceived as close to the group's core engaging in gambling may help convert Deniers to become Objectors (i.e., those for whom BAFTing is acceptable but not personally worthwhile).

Further, in consideration of fan aggression that stems from the decrease in emotion following a loss (Card \& Dahl, 2011; Wann et al., 2011), HAFFing could be a way to allow fans at high risk for fan aggression to hedge the loss and reduce the likelihood of post-game violence. Such an extension of HAFFing could be immediately applicable to event managers, sport 
organizations, and established fans groups seeking ways to reduce fan violence, especially in sports where hooliganism is a persistent problem.

On a broader scale, this research underscores the need for continued investigation of individuals' techniques to deal with loss to their self-image, particularly as related to the proactive action of HAFFing. Future research could build personality profiles that include potential moderating variables such as predisposition to rationality (Gigerenzer \& Selten, 2002), levels of optimism (Massey et al., 2011), risk and loss aversion (Coates et al., 2014), and sport fan motives (Wann, 1995). We encourage broad random sampling to identify the incidence of HAFFing, especially in countries where sport gambling is legal and those where it is not. While our sample provided a description of the activity and understanding of the participants' motives, it is also possible there are other types of BAFTers who we do not fully understand, and that other forms of HAFFing exist. We focused on only an individual's single strongest team identity leading to opportunities for future research to investigate fan identification with individuals on a team, individual sport athletes, or any of the complexities of multiple, overlapping identities (e.g., Delia, 2015). Other factors may also play a role in BAFTing, including the type/amount of the bet, frequency of gambling, length of the season, or the specific sport involved.

Finally, we explicitly instructed respondents to not consider fantasy sports as part of their BAFTing behaviors. Fantasy sports players often have financial investments in their fantasy teams and occasionally prefer their fantasy football team to be more successful than their favorite team (e.g., Drayer et al., 2010, p. 138), which some view as a form of BAFTing. While we agree that fantasy sports potentially incentivize fans to select and root for rival teams and players in order to achieve financial success, we cannot generalize this research to fantasy sports. Yet, as daily fantasy games increase in popularity and sports properties take investments in these 
pseudo-gambling businesses (Fisher, 2015), understanding the interplay between BAFTing and fantasy sports becomes all the more important.

\section{Conclusion}

Our mixed-method exploratory investigation of the phenomenon of highly identified fans who BAFT found two distinct motives for this seemingly non-normative behavior. Gamblers BAFT for reasons un-related to fandom. Hedgers, on the other hand, engage in BAFTing precisely because they are fans. This emotional hedging is a newly recognized form of selfimage management utilized by highly identified fans to proactively regulate their psychological health. In contrast to existing, reactive forms of self-image management such as BIRGing, CORFing, CORSing, BIRFing, Blasting, and Boosting, HAFFing requires foresight, planning, and action to manage one's future expected mood in the face of an expected loss.

As unintuitive as HAFFing may appear at first glance, it aligns with our known understanding of SIT. HAFFers dealing with a potential loss do not view themselves as selfcriticizing because a) their view of the fan prototype does not prohibit BAFTing, b) they still want their team to win, and c) they prefer that their team wins and they lose money on their wager. The identification of HAFFing as a new form of self-image management advances the stream of research on social identity and prototypical fan behavior. Furthermore, it offers professional sport organizations more insight into managing highly identified fans and the expenditures they make to maintain their identity. 


\section{References}

Abrams, D., \& Hogg, M. A. (1988). Comments on the motivational status of self-esteem in social identity and intergroup discrimination. European Journal of Social Psychology, 18, 317-334.

Ashmore, R. D., Deaux, K., \& McLaughlin-Volpe, T. (2004). An organizing framework for collective identity: Articulation and significance of multidimensionality. Psychological Bulletin, 130, 80-114.

Back, K., Lee, C., \& Stinchfield, R. (2011). Gambling motivation and passion: A comparison study of recreational and pathological gamblers. Journal of Gambling Studies, 27, 355370

Baumeister, R. F., \& Leary, M. R. (1995). The need to belong: Desire for interpersonal attachments as a fundamental human motivation. Psychological Bulletin, 117, 497-529.

Bosman, R., \& van Winden, F. (2002). Emotional hazard in a power-to-take experiment. The Economic Journal, 112, 147-169.

Branscombe, N. R., \& Wann, D. L. (1992). Role of identification with a group, arousal, categorization processes, and self-esteem in sports spectator aggression. Human Relations, 45, 1013-1033.

Campbell, R. M., Aiken, D., \& Kent, A. (2004). Beyond BIRGing and CORFing: Continuing the exploration of fan behavior. Sport Marketing Quarterly, 13, 151-157.

Card, D., \& Dahl, G. B. (2011). Family violence and football: The effect of unexpected emotional cues on violent behavior. The Quarterly Journal of Economics, 126, 1-41.

Cialdini, R. B. (1989). Indirect tactics of image management: Beyond basking. In R. A. Giacalone \& P. Rosenfeld (Eds.), Impression management in the organization. Hillsdale, NJ: Lawrence Erlbaum Associates.

Cialdini, R. B., Borden, R. J., Thorne, A., Walker, M. R., Freeman, S., \& Sloan, L. R. (1976). Basking in reflected glory: Three (football) studies. Journal of Personality and Social Psychology, 34, 366-375.

Cialdini, R. B., \& Richardson, K. D. (1980). Two indirect tactics of image management: Basking and blasting. Journal of Personality and Social Psychology, 39, 366-375.

Coates, D., Humphreys, B. R., \& Zhou, L. (2014). Reference-dependent preferences, loss aversion, and live game attendance. Economic Inquiry, 52, 959-973.

Cohn, B. (2015, June 20). Legalized sports gambling across U.S. could soon become reality. TribLive, http://triblive.com/sports/nationworldsports/8532839-74/sports-bettinggambling Accessed 2015.08.31. 
Conlisk, J. (1993). The utility of gambling. Journal of Risk and Uncertainty, 6, 255-275.

Coyne, I. T. (1997). Sampling in qualitative research. Purposeful and theoretical sampling; merging or clear boundaries? Journal of Advanced Nursing, 26, 623-630. doi:10.1046/j.1365-2648.1997.t01-25-00999.x

Creswell, J. W. (2013). Research design: Qualitative, quantitative, and mixed methods approaches. Thousand Oaks: Sage.

Delia, E. B. (2015). The exclusiveness of group identity in celebrations of team success. Sport Management Review, 18, 396-406.

Denzin, N. K., \& Lincoln, Y. S. (2011). Handbook of qualitative research. Thousand Oaks, CA: Sage.

Doyle, J., Lock, D., Filo, K., Funk, D., \& McDonald, H. (2016). 'I was there from the start': The identity maintenance strategies used by fans to combat the threat of losing. Sport Management Review. http://dx.doi.org/10.1016/j.smr.2016.04.006

Drayer, J., Shapiro, S. L., Dwyer, B., Morse, A. L., \& White, J. (2010). The effects of fantasy football participation on NFL consumption: A qualitative analysis. Sport Management Review, 13, 129-141.

Finch, J. F., \& Cialdini, R. B. (1989). Another indirect tactic of (self-) image management: Boosting. Personality and Social Psychology Bulletin, 15, 222-232.

Fisher, E. (2015, July 22). DraftKings closes on \$300M funding round. SportsBusiness Journal, http://www.sportsbusinessdaily.com/Journal/Issues/2015/07/27/Finance/DraftKings.aspx Accessed 2016.07.25.

Funk, D. C., \& James, J. (2001). The psychological continuum model: A conceptual framework for understanding an individual's psychological connection to sport. Sport Management Review, 4, 119-150.

Gigerenzer, G., \& Selten, R. (2002). Bounded rationality: The adaptive toolbox. MIT Press.

Hewstone, M., Rubin, M., \& Willis, H. (2002). Intergroup bias. Annual Review of Psychology, $53,575-604$.

Havard, C. T. (2014). Glory Out of Reflected Failure: The examination of how rivalry affects sport fans. Sport Management Review, 17, 243-253.

Hirt, E. R., Zillmann, D., Erickson, G. A., \& Kennedy, C. (1992). Costs and benefits of allegiance: Changes in fans' self-ascribed competencies after team victory versus defeat. Journal of Personality and Social Psychology, 63, 724-738.

Hogg, M. A. (2003). Social identity. In M. R. Leary \& J. P. Tangney (Eds.), Handbook of self and identity (pp. 462-479). New York: Guilford. 
Hogg, M. A., \& Terry, D. J. (2000). Social identity and self-categorization processes in organizational contexts. Academy of Management Review, 25, 121-140.

Humphreys, B. R., Paul, R. J., \& Weinbach, A. P. (2013). Consumption benefits and gambling: Evidence from the NCAA basketball betting market. Journal of Economic Psychology, 39, 376-386.

Inglis, S. (1992). Focus groups as a useful qualitative methodology in sport management. Journal of Sport Management, 6, 173-178.

Jetten, J., Spears, R., \& Manstead A. S. R. (1998). Defining dimensions of distinctiveness: Group variability makes a difference to differentiation. Journal of Personality and Social Psychology, 74, 1481-1492.

Lee, C. K., Lee, Y. K., Bernhard, B. J., \& Yoon, Y. S. (2006). Segmenting casino gamblers by motivation: A cluster analysis of Korean gamblers. Tourism Management, 27, 856-866.

Lefton, T. (2015, January 12). As leagues embrace daily fantasy, a call for transparency. SportsBusiness Journal, http://www.sportsbusinessdaily.com/Journal/Issues/2015/01/12/Marketing-andSponsorship/The-Lefton-Report.aspx Accessed 2016.07.25.

Loroz, P. S. (2004). Golden-age gambling: Psychological benefits and self-concept dynamics in aging consumers' consumption experiences. Psychology and Marketing, 21, 323-349.

Mao, L. L., Zhang, J. J., \& Connaughton, D. P. (2015). Sports gambling as consumption: Evidence from demand for sports lottery. Sport Management Review, 18, 436-447.

Marques, J., Abrams, D., Paez, D., \& Martinez-Taboada, C. (1998). The role of categorization and in-group norms in judgments of groups and their members. Journal of Personality and Social Psychology, 75, 976-988.

Massey, C., Simmons, J. P., \& Armor, D. A. (2011). Hope over experience: Desirability and the persistence of optimism. Psychological Science, 22(2), 274-281.

McDonald, H., Karg, A. J., \& Vocino, A. (2013). Measuring season ticket holder satisfaction: Rationale, scale development and longitudinal validation. Sport Management Review, 16, 41-53.

Neighbors, C., Lostutter, T. W., Cronce, J. M., \& Larimer, M. E. (2002). Exploring college student gambling motivation. Journal of Gambling Studies, 18, 361-370.

Park, M. K., Yang, X., Lee, B. K., Jang, H. C., \& Stokowski, P. A. (2002). Segmenting casino gamblers by involvement profiles: A Colorado example. Tourism Management, 23, 5565. 
Platz, L., \& Millar, M. (2001). Gambling in the context of other recreation activity: A quantitative comparison of casual and pathological student gamblers. Journal of Leisure Research, 33, 383-395.

Pons, F., Giroux, M., Maltese, L., \& Mourali, M. (2014). Toward a typology of dysfunctional fans in professional football. In Book of abstracts, $22^{\text {nd }}$ annual conference of the European Association of Sport Management (pp. 7-8). Coventry, UK: EASM.

Roccas, S., \& Brewer, M. B. (2002). Social identity complexity. Personality and Social Psychology Review, 6(2), 88-106.

Rudd, A., \& Johnson, R. B. (2010). A call for more mixed methods in sport management research. Sport Management Review, 13, 14-24.

Sapolsky, B. S. (1980). The effect of spectator disposition and suspense on the enjoyment of sport contests. International Journal of Sport Psychology, 11, 1-10.

Sedikides, C., \& Brewer, M. B. (2001). Individual self, relational self, and collective self: Partners, opponents, or strangers? In C. Sedikides \& M. B. Brewer (Eds.), Individual self, relational self, collective self (pp. 1-4). Philadelphia: Psychology Press.

Silver explains betting stance, says legalization could be good for business. (2015, April 21). SportsBusiness Daily, http://www.sportsbusinessdaily.com/Daily/Issues/2015/04/21/Leagues-and-GoverningBodies/NBA-Betting.aspx Accessed 2015.08.31.

Snyder, C. R., Lassegard, M., \& Ford, C. E. (1986). Distancing after group success and failure: Basking in reflected glory and cutting off reflected failure. Journal of Personality and Social Psychology, 51, 382-388.

Stewart, S. H., \& Zack, M. (2008). Development and psychometric evaluation of a threedimensional Gambling Motives Questionnaire. Addiction, 103, 1110-1117.

Tajfel, H., \& Turner, J. C. (1986). The social identity theory of intergroup behavior. In S. Worchel, \& W. G. Austin (Eds.), Psychology of intergroup relations, 2nd ed. (pp. 7-24). Chicago, IL: Nelson-Hall.

Trail, G. T., Kim, Y. K., Kwon, H. H., Harrolle, M. G., Braunstein-Minkove, J. R., \& Dick, R. (2012). The effects of vicarious achievement on BIRGing and CORFing: Testing moderating and mediating effects of team identification. Sport Management Review, 15, 345-354.

Turner, J. C. (1982). Towards a cognitive redefinition of the social group. In H. Tajfel (Ed.), Social Identity and Intergroup Relations (pp. 15-40). Cambridge, UK: Cambridge University Press.

Unruh, D. R. (1980). The nature of social worlds. Pacific Sociological Review, 23, 271-296. 
Van Leeuwen, L., Quick, S., \& Daniel, K. (2002). The sport spectator satisfaction model: A conceptual framework for understanding the satisfaction of spectators. Sport Management Review, 5(2), 99-128.

Wakefield, K. L., \& Wann, D. L. (2006). An examination of dysfunctional sport fans: Method of classification and relationships with problem behaviors. Journal of Leisure Research, 38, 168-186.

Wann, D. L. (2006). Understanding the positive social psychological benefits of sport team identification: The team identification-social psychological health model. Group Dynamics: Theory, Research, and Practice, 10, 272-296.

Wann, D. L. (1995). Preliminary validation of the Sport Fan Motivation Scale. Journal of Sport \& Social Issues, 19, 377-396.

Wann, D. L., \& Branscombe, N. R. (1990). Die-hard and fair-weather fans: Effects of identification on BIRGing and CORFing tendencies. Journal of Sport \& Social Issues, $14,103-117$.

Wann, D. L., \& Branscombe, N. R. (1993). Sports fans: Measuring degree of identification with their team. International Journal of Sport Psychology, 24, 1-17.

Wann, D. L., \& Branscombe, N. R. (1995). Influence of identification with a sports team on objective knowledge and subjective beliefs. International Journal of Sport Psychology, 26, 551-567.

Wann, D. L., Grieve, F. G., Zapalac, R. K., End, C., Lanter, J. R., Pease, D. G., Fellows, B., Oliver, K., \& Wallace, A. (2013). Examining the superstitions of sport fans: Types of superstitions, perceptions of impact, and relationship with team identification. Athletic Insight, 5, 21-44.

Wann, D. L., Hamlet, M. A., Wilson, T., \& Hodges, J. A. (1995). Basking in reflected glory, cutting off reflected failure, and cutting off future failure: The importance of identification with a group. Social Behavior and Personality: An International Journal, 23, 377-388.

Wann, D. L., Melnick, M. J., Russell, G. W., \& Pease, D. G. (2001). Sport fans: The psychology and social impact of spectators. London: Routledge.

Wann, D. L., Morris-Shirkey, P. A., Peters, E. J., \& Suggs, W. L. (2002). Highly identified sport fans and their conflict between expression of sport knowledge and biased assessments of team performance. International Sports Journal, 6, 153-159.

Yoshida, M., Gordon, B., Nakazawa, M., \& Biscaia, R. (2014). Conceptualization and measurement of fan engagement: Empirical evidence from a professional sport context. Journal of Sport Management, 28, 399-417. 


\section{Tables}

Table 1: Descriptive statistics of highly identified fans who have placed financial wagers on sports $(\mathrm{n}=190)$

\begin{tabular}{lll}
\hline & Non-BAFTers & BAFTers \\
\hline $\mathrm{N}$ & 150 & 40 \\
Average ID & 48.2 & 48.3 \\
Sport Wagers Per Year & & \\
Max & 300 & 1500 \\
Min & 1 & 1 \\
Average & 10 & 75 \\
Median & 3 & 8
\end{tabular}

BAFT Wagers Ever

Max

Min 1

Average

10

Median

4

Note: Data from survey responses. There was no significant difference between the identification scores of BAFTers and non-BAFTers in the surveys $(t(188)=0.100, \mathrm{p}=.92)$ or focus groups $(t(10)=0.272, \mathrm{p}=.79)$. 
Table 2: Coding structure of beliefs of BAFTers and non-BAFTers

\begin{tabular}{|c|c|c|}
\hline \multirow[b]{2}{*}{ Parent node } & \multicolumn{2}{|c|}{ Sample codes } \\
\hline & Axial & Open \\
\hline Highly & Want the team to win & belief, faith, optimism, positive thinking \\
\hline Identified Fan & Loss decreases emotional state & emotional loss, upset \\
\hline \multirow[t]{4}{*}{ BAFTer } & It is acceptable for a prototypical fan to BAFT & logic, rationality, separate emotion and logic \\
\hline & Expert knowledge suggests team will lose & "know" the outcome; team is going to lose \\
\hline & Money can compensate for emotional loss & hedging, win-win, regulate emotions, coping strategy \\
\hline & Gambling motives take precedence over fandom & heightened emotion, enhancement, money \\
\hline \multirow[t]{6}{*}{ Non-BAFTer } & Idea of BAFTing creates internal conflict & betrayal, criticism, guilt, decreased mood \\
\hline & Superstition & jinxing, bad luck, karma \\
\hline & BAFTing requires rooting against team & cannot root against team \\
\hline & It is not acceptable for a prototypical fan to BAFT & integrity, true fan, respect, loyalty, morals, purity, trust \\
\hline & Cannot contemplate possibility of a loss & confidence, optimism \\
\hline & Money cannot compensate for emotional loss & wins more important, lose-lose \\
\hline
\end{tabular}

Note. The Highly Identified Fan parent node refers to all highly identified fans whether they are BAFTers or non-BAFTers. Coding derived from focus groups and open-ended survey responses. 
Table 3: Types of highly identified fans who gamble on sports as related to BAFTing

\begin{tabular}{|c|c|c|}
\hline Term & Description & Decision Process \\
\hline \multicolumn{3}{|l|}{ BAFTers } \\
\hline Hedgers & BAFT to regulate emotion & Loss $<$ Loss $+\$<$ Win $-\$<$ Win \\
\hline Gamblers & $\begin{array}{l}\text { Emphasize financial gains } \\
\text { irrespective of team affiliation }\end{array}$ & Win or Loss $\quad \mid \$$ \\
\hline \multicolumn{3}{|c|}{ Non-BAFTers } \\
\hline Deniers & Cannot fathom any fan BAFTing & $\begin{array}{l}\text { Win > Loss (no calculation for } \\
\text { BAFTing) }\end{array}$ \\
\hline Objectors & $\begin{array}{l}\text { Recognize BAFTing, but choose } \\
\text { not to (no exchange rate) }\end{array}$ & Loss $=$ Loss $+\$=$ Win $-\$<$ Win \\
\hline
\end{tabular}


Table 4: Indirect self-image management behaviors

\begin{tabular}{|c|c|c|c|c|}
\hline Behavior & Situation & Timing & Visibility & Key literature \\
\hline $\begin{array}{l}\text { HAFFing (Hedging } \\
\text { Against Future } \\
\text { Failure) }\end{array}$ & $\begin{array}{l}\text { Before potential } \\
\text { team failure }\end{array}$ & Proactive & $\begin{array}{l}\text { Private, but } \\
\text { can be public }\end{array}$ & Agha \& Tyler \\
\hline $\begin{array}{l}\text { COFFing (Cutting } \\
\text { Off Future Failure) }\end{array}$ & $\begin{array}{l}\text { Before potential } \\
\text { team failure and } \\
\text { after team success }\end{array}$ & $\begin{array}{l}\text { Proactive } \\
\text { and } \\
\text { Reactive }\end{array}$ & $\begin{array}{l}\text { Private (as } \\
\text { defined by the } \\
\text { absence of } \\
\text { public } \\
\text { expression) }\end{array}$ & $\begin{array}{l}\text { Wann, Hamlet, Wilson, } \\
\text { \& Hodges, } 1995\end{array}$ \\
\hline $\begin{array}{l}\text { BIRGing (Basking } \\
\text { In Reflected } \\
\text { Glory); Boasting }\end{array}$ & After team success & Reactive & Public & $\begin{array}{l}\text { Cialdini et al., 1976; } \\
\text { Cialdini, } 1989\end{array}$ \\
\hline $\begin{array}{l}\text { CORSing (Cutting } \\
\text { Off Reflected } \\
\text { Success) }\end{array}$ & After team success & Reactive & Public & $\begin{array}{l}\text { Campbell, Aiken, \& } \\
\text { Kent, } 2004\end{array}$ \\
\hline $\begin{array}{l}\text { BIRFing (Basking } \\
\text { In Spite of } \\
\text { Reflected Failure) }\end{array}$ & After team failure & Reactive & Public & $\begin{array}{l}\text { Campbell, Aiken, \& } \\
\text { Kent, } 2004\end{array}$ \\
\hline Boosting & After team failure & Reactive & Public & Finch \& Cialdini, 1989 \\
\hline Burnishing & After team failure & Reactive & Public & $\begin{array}{l}\text { Cialdini \& Richardson, } \\
1980\end{array}$ \\
\hline $\begin{array}{l}\text { CORFing (Cutting } \\
\text { Off Reflected } \\
\text { Failure); Burying }\end{array}$ & After team failure & Reactive & Public & $\begin{array}{l}\text { Snyder, Lassegard, \& } \\
\text { Ford, 1986; Cialdini, } \\
1989\end{array}$ \\
\hline Blasting & After team failure & Reactive & Public & $\begin{array}{l}\text { Cialdini \& Richardson, } \\
1980\end{array}$ \\
\hline $\begin{array}{l}\text { Glory out of } \\
\text { Reflected Failure } \\
\text { (GORFing); } \\
\text { Blaring }\end{array}$ & $\begin{array}{l}\text { After rival team's } \\
\text { failure }\end{array}$ & Reactive & Public & $\begin{array}{l}\text { Havard, 2014; Cialdini, } \\
1989\end{array}$ \\
\hline
\end{tabular}

